\title{
STRATEGI PENDANAAN INVESTASI TUGBOAT DAN TONGKANG DI PTMS
}

\author{
Adityo Reksoprawiro \\ Program Studi S2 Magister Manajemen Wijawiyata Manajemen \\ Sekolah Tinggi Manajemen PPM \\ Pratiwi Laksana \\ Program Studi S2 Magister Manajemen Wijawiyata Manajemen \\ Sekolah Tinggi Manajemen PPM
}

\begin{abstract}
Tujuan studi ini adalah memperoleh instrumen utang dan ekuitas untuk yang tepat untuk pendanaan proyek investasi tugboat dan tongkang PTMS, memperoleh komposisi/struktur pendanaan yang tepat untuk proyek investasi tugboat dan tongkang PTMS, mendesain action plan untuk proses perolehan dana proyek investasi tugboat dan tongkang PTMS. Metode yang digunakan adalah analytical hierarchy process yang digunakan sebagai pengambilan keputusan untuk pemilihan instrumen pendanaan yang digunakan, dan pemilihan struktur pendanaan yang tepat untuk mendanai proyek investasi dengan pendekatan cost of capital. Hasil yang didapatkan adalah sesuai dengan kondisi internal dan eksternal perusahaan,bahwa instrumen yang digunakan adalah saham biasa dan hutang bank, sedangkan struktur pendanaan yang tepat untuk membiayai proyek tersebut adalah $90 \%$ saham dan $10 \%$ utang bank.
\end{abstract}

Keywords:

Strategi pendanaan, investasi, analytical hierarchy process, tugboat dan tongkang 


\section{PENDAHULUAN}

PTMS adalah perusahan yang bergerak di bidang jual-beli (trading) batubara. Saat ini sebagian besar kegiatan usaha PTMS berada di Kalimantan Tengah. Karakteristik pulau Kalimantan yang memiliki banyak sungai menjadikannya sebagai kekuatan dalam mendukung proses pendistribusian batubara.

Distribusi batubara PTMS dilakukan melalui jalur sungai dan laut tentu juga membutuhkan alat angkut. Alat angkut yang digunakan adalah tugboat dan tongkang. Investasi tugboat dan tongkang

Untuk kegiatan distribusi batubara PTMS tentu saja memerlukan dana yang sangat besar. Tugboat dan tongkang termasuk golongan aktiva tetap yang di dalam neraca memiliki sifat permanen dan dapat digunakan terus menerus selama taksiran umur ekonomisnya, sehingga dalam pengadaan dan pendanaannya harus dilakukan dengan cermat.

Studi kelaikan investasi tugboat dan tongkang untuk proses distribusi PTMS telah dilakukan pada Kerja Praktek dan dihasilkan keputusan bahwa investasi satu set tugboat dan tongkang ukuran 270 feet untuk proses feeder dan transhipment PTMS laik untuk dilakukan. Untuk menjalankan proyek investasi tersebut, yang penting untuk diperhatikan adalah mengenai strategi pendanaan proyek investasi tersebut, karena strategi pendanaan yang tepat dapat meningkatkan keuntungan dari perusahaan.

Sumber dana atau modal untuk kegiatan investasi perusahaan dapat berasal dari dua sumber utama, yaitu utang dan ekuitas. Setiap jenis sumber modal tersebut menimbulkan biaya. Maka untuk memperoleh biaya modal yang minimal namun bisa menghasilkan keuntungan yang maksimal, perlu dilakukan perhitungan agar diperoleh keputusan yang tepat dalam penggunaan utang dan ekuitas tersebut.

\section{TINJAUAN PERUSAHAAN}

Berdasarkan analisa sebelumnya yang dilakukan pada Kerja Praktek, diperoleh tiga proyek investasi tugboat dan tongkang untuk mendukung tiga proses distribusi PTMS yang berbeda, yaitu :

a. Satu set tugboat dan tongkang berukuran 270 feet untuk mendukung proses shipment Timbau-Gresik.

b. Satu set tugboat dan tongkang berukuran 270 feet untuk mendukung proses transhipment Timbau-Taboneo dan feeder Ninggi-Timbau.

c. Satu set tugboat dan tongkang berukuran 210 feet untuk mendukung proses feeder Ninggi-Timbau.

Dari hasil studi kelaikan bisnis yang dilakukan diperoleh hasil bahwa proyek nomor 1 dan 2 laik untuk dilakukan, sedangkan proyek nomor 3 tidak laik untuk dilakukan. Namun keterbatasan dana dan kondisi internal perusahaan tidak memungkinkan perusahaan untuk mengeksekusi kedua proyek investasi tersebut secara bersamaan. Maka dari itu, dari dua proyek tersebut dipilih satu proyek yang lebih diprioritaskan, yaitu proyek investasi satu set tugboat dan tongkang berukuran 270 feet untuk mendukung proses transhipment Timbau-Taboneo dan feeder NinggiTimbau.

Besar dana yang dibutuhkan untuk melakukan investasi sebesar 20.145.000.000 IDR. Biaya ini merupakan biaya yang diperlukan untuk membeli tugboat sebesar 19.650.000.000 IDR dan tongkang serta biaya-biaya administrasi atau biaya lainnya yang diperlukan dalam pengadaan tugboat dan tongkang tersebut sebesar 495.000.000 IDR. 


\section{TINJAUAN PUSTAKA}

\subsection{Investasi dan Pendanaan}

Secara umum, investasi adalah penanaman modal (baik modal tetap maupun modal tidak tetap) yang digunakan dalam proses produksi untuk memperoleh keuntungan suatu perusahaan. Menurut Halim (2005), investasi pada hakikatnya merupakan penempatan sejumlah dana pada saat ini dengan harapan untuk memperoleh keuntungan di masa mendatang.

Ada dua keputusan finansial yang terkait dengan kegiatan investasi, yaitu keputusan investasi dan keputusan pembiayaan. Menurut Sundjaja dan Barlian (2003), keputusan investasi dan keputusan pembiayaan didefinisikan sebagai berikut :

a. Keputusan investasi adalah memilih alternatif investasi yang terbaik didasarkan pada nilai ekonomis bagi perusahaan atau yang disebut nilai investasi.

b. Keputusan pembiayaan adalah menentukan jumlah dan sumber modal yang dibutuhkan untuk membiayai alternatif investasi yang dipilih.

Menurut Riyanto (2001), jenis-jenis modal dapat dibagi menjadi :

a. Modal Asing

Modal asing adalah modal yang berasal dari luar perusahaan yang sifatnya sementara di dalam perusahaan, dan bagi perusahaan yang bersangkutan modal tersebut merupakan utang, yang pada saatnya harus di bayar kembali. Modal asing dibagi lagi kedalam Utang jangka pendek, dan utang jangka panjang. Utang jangka panjang dibagi lagi kedalam utang obligasi dan hutang hipotik.

b. Modal Sendiri

Modal sendiri selain berasal dari luar perusahaan dapat juga berasal dari modal yang dihasilkan dan dibentuk sendiri di dalam perusahaan. Modal sendiri yang berasal dari sumber intern ialah dalam bentuk keuntungan yang dihasilkan perusahaan (modal saham, cadangan dan laba ditahan). Adapun modal yang berasal dari sumber ekstern ialah modal yang berasal dari pemilik perusahaan.

\subsection{Proses Hierarki Analitik}

Metode Analytic Hierarchy Process

(AHP) atau Proses Hierarki Analitik ini dikembangkan di Sekolah Bisnis Wharton oleh Thomas Saaty pada tahun 1970-an, memperkenalkan model pengambilan keputusan dari sebuah permasalahan yang kompleks ke dalam sebuah struktur hierarki yang menunjukkan suatu hubungan dari tujuan, objective (kriteria), sub-objective dan alternative, dimana faktor ketidakpastian dan pengaruh lain dapat dicakupkan. AHP memungkinkan proses pengambilan keputusan mendapat skala prioritas atau bobot berdasarkan nilai perbandingan antar kriteria (Forman, 1995).

Langkah-langkah yang dilakukan adalah sebagai berikut :

a. Mendefinisikan suatu kegiatan yang memerlukan pemilihan dalam pengambilan keputusan atau mendefinisikan tujuan/fokus dari penggunaan metode AHP.

b. Menentukan alternatif-alternatif pilihan.

c. Menentukan kriteria dari pilihan-pilihan tersebut terhadap identitas kegiatan membuat hierarkinya.

d. Membuat matriks pairwise comparison berdasarkan kriteria di tingkat atasnya dengan memperhatikan prinsip-prinsip comparative judgment dan local consistency (Tabel 1.) 
Tabel 1.

Metode Pair Comparison

\begin{tabular}{|c||c||c||c||c|c||}
\hline $\begin{array}{c}\text { KECEP } \\
\text { ATAN }\end{array}$ & Mandiri & BRI & BCA & BNI & $\begin{array}{c}\text { CIMB } \\
\text { Niaga }\end{array}$ \\
\hline Mandiri & 1 & $1 / 2$ & $1 / 7$ & 1 & $1 / 2$ \\
\hline BRI & 2 & 1 & $1 / 6$ & 2 & 1 \\
\hline \hline BCA & 7 & 6 & 1 & 7 & 6 \\
\hline BNI & 1 & $1 / 2$ & $1 / 7$ & 1 & $1 / 2$ \\
\hline $\begin{array}{c}\text { CIMB } \\
\text { Niaga }\end{array}$ & 2 & 1 & $1 / 6$ & 2 & 1 \\
\hline
\end{tabular}

Berdasarkan kriteria kecepatan, bank BRI 1/2 kali lebih cepat dari bank Mandiri, bank BCA 1/7 kali lebih cepat dari bank BNI sama cepatnya dengan bank Mandiri, dan Bank CIMB Niaga 1/2 kali lebih cepat dari bank Mandiri, dst.setelah dilakukan pair comparison maka dicari eigenvector, sehingga menghasilkan tingkat kepentingan yang berbeda antara kriteria dan alternatif yang ada.

\subsection{FRICTO ANALYSIS}

Menurut Ketser dan George (2005), salah satu kerangka kerja yang sangat berguna dalam menganalisis faktor-faktor yang berpengaruh dalam penentuan keputusan pembiayaan adalah "FRICTO Analysis". FRICTO adalah singkatan dari flexibilty, risk, income, control, timing, dan other. Ditetapkanlah bahwa kriteria-kriteria yang digunakan dalam pengambilan keputusan strategi pendanaan ini adalah menggunakan komponen dalam FRICTO Analysis tersebut, dengan penjelasan di bawah ini :

\section{a. Flexibilty}

Berkaitan dengan kebijakan manajemen dalam hal keputusan pembiayaan di masa yang akan datang.

Dalam hal ini fleksibilitas dapat diukur dengan peringkat kredit perusahaan. Strategi pendanaan yang menghasilkan peringkat kredit yang lebih tinggi, berarti lebih baik bagi perusahaan, karena dengan peringkat kredit yang tinggi akan meningkatkan peluang perusahaan untuk mendapat pinjaman di masa yang akan datang, serta biaya pinjaman yang harus ditanggung perusahaan lebih rendah.

Menurut Damodaran (2002), peringkat kredit perusahaan dapat diukur dengan menghitung ICR (interest coverage ratio), dimana EBIT dibagi beban bunga. Lalu peringkat kredit perusahaan ditentukan sesuai nilai ICR perusahaan.

Setiap alternatif kombinasi sumber pendanaan akan menghasilkan interest expense yang berbeda, sehingga menghasilkan nilai ICR dan peringkat kredit perusahaan yang berbeda pula. Semakin tinggi peringkat kredit perusahaan, semakin baik.

b. Risk

Penggunaan utang dalam membiayai perusahaan juga menimbulkan risiko keuangan bagi perusahaan. Besarnya risiko yang dihadapi perusahaan dapat diukur dengan menghitung risk of bankruptcy.

Menurut White (2003), risiko kebangkrutan (risk of bankruptcy) perusahaan dapat dihitung dengan metode Altman's Z-Score. Z-model original didesain untuk menghitung risiko kebangkrutan pada perusahaan manufacturing yang sudah go public. PTMS merupakan perusahaan yang bergerak dalam bidang trading batubara dan belum go public, sehingga untuk menghitung 
risk of bankcruptcy PTMS digunakan Z'model untuk menghitung risiko kebangkrutan pada perusahaan yang tidak go-public (private firm) :

c. Income

Income perusahaan dipengaruhi oleh struktur pendanaan perusahaan. Penggunaan utang dapat memberikan keuntungan bagi perusahaan karena pembayaran biaya bunga pinjaman dapat mengurangi pembayaran biaya pajak, sedangkan penggunaan ekuitas tidak dapat mengurangi pajak. Pada kondisi tertentu peningkatan penggunaan utang juga dapat meningkatkan EPS perusahaan.

Pada rasio penggunaan utang dan ekuitas tertentu akan menghasilkan COC terendah sehingga menghasilkan keuntungan tertinggi bagi perusahaan.

\section{d. Control}

Pertimbangan control perusahaan adalah keputusan manajemen yang diambil oleh para pemegang saham. Jika manajemen memiliki mayoritas jumlah saham yang beredar (outstanding share), maka manajemen harus mempertimbangkan kemampuan mereka dalam mengontrol perusahaan karena dampak penambahan utang atau ekuitas pada struktur modal.

\section{e. Timing}

Timing menjadi begitu penting sebagai pertimbangan manajer dalam menetapkan keputusan pembiayaan, hal ini disebabkan karena pasar modal, baik pasar saham ataupun obligasi, bergerak fluktuatif dipengaruhi berbagai faktor eksternal. Jika tingkat suku bunga sedang melambung, maka manajer akan menghidari penerbitan utang jangka panjang. Begitu juga dengan pasar ekuitas, kondisi dan tren yang tidak baik pada pasar ekuitas secara keseluruhan dapat berdampak negatif jika melakukan keputusan pembiayaan melalui ekuitas (issuing stock). Hal yang patut diingat adalah kondisi pasar modal yang sedang terjadi dan peluang apa yang mungkin terjadi di masa datang.

f. Other

Other, yaitu hal lain yang dapat dijadikan pertimbangan manajemen dalam keputusan pembiayaan selain lima faktor dalam FRICTO Analysis yang telah dibahas sebelumnya. Faktor lainnya ini digunakan untuk memasukkan faktor yang kiranya penting dalam pengambilan keputusan.

\section{KERANGKA ANALISIS}

Setelah diketahui bahwa dana yang dibutuhkan adalah sebesar 20.145.000.000 IDR, maka dilakukan proses pemilihan sumber dana atau instrumen pendanaan yang akan digunakan berdasarkan kondisi PTMS itu sendiri. Menurut kebijakan manajemen PTMS, penggunanaan utang untuk mendanai proyek investasi tugboat dan tongkang ini dapat diperoleh hanya dari utang bank jangka panjang. Hal ini disebabkan karena dana yang dibutuhkan untuk menerbitkan obligasi, termasuk di dalamnya biaya underwritter sangat besar. Kebutuhan dana investasi yang berkisar 20 milyar IDR dapat dikatakan kurang besar (kurang sizeable) untuk didanai dengan obligasi. Hal-hal yang harus dilakukan pasca penerbitan obligasi juga tidak sedikit, seperti laporan keuangan yang harus selalu tersedia per 3 bulan. Selain itu PTMS yang baru berjalan kurang dari 3 tahun, jika saat ini mengeluarkan obligasi dinilai kurang marketable jika dibandingkan obligasi lain yang ada di pasar modal.

Sedangkan untuk penggunaan ekuitas, yang dapat digunakan adalah hanya saham biasa. Hal ini disebabkan karena PTMS memang tidak mengeluarkan saham preferen. Selain itu besarnya laba ditahan yang dimiliki PTMS saat ini adalah sebesar 3.393.585.645 IDR atau sebesar 16,85\% dari kebutuhan dana investasi, 


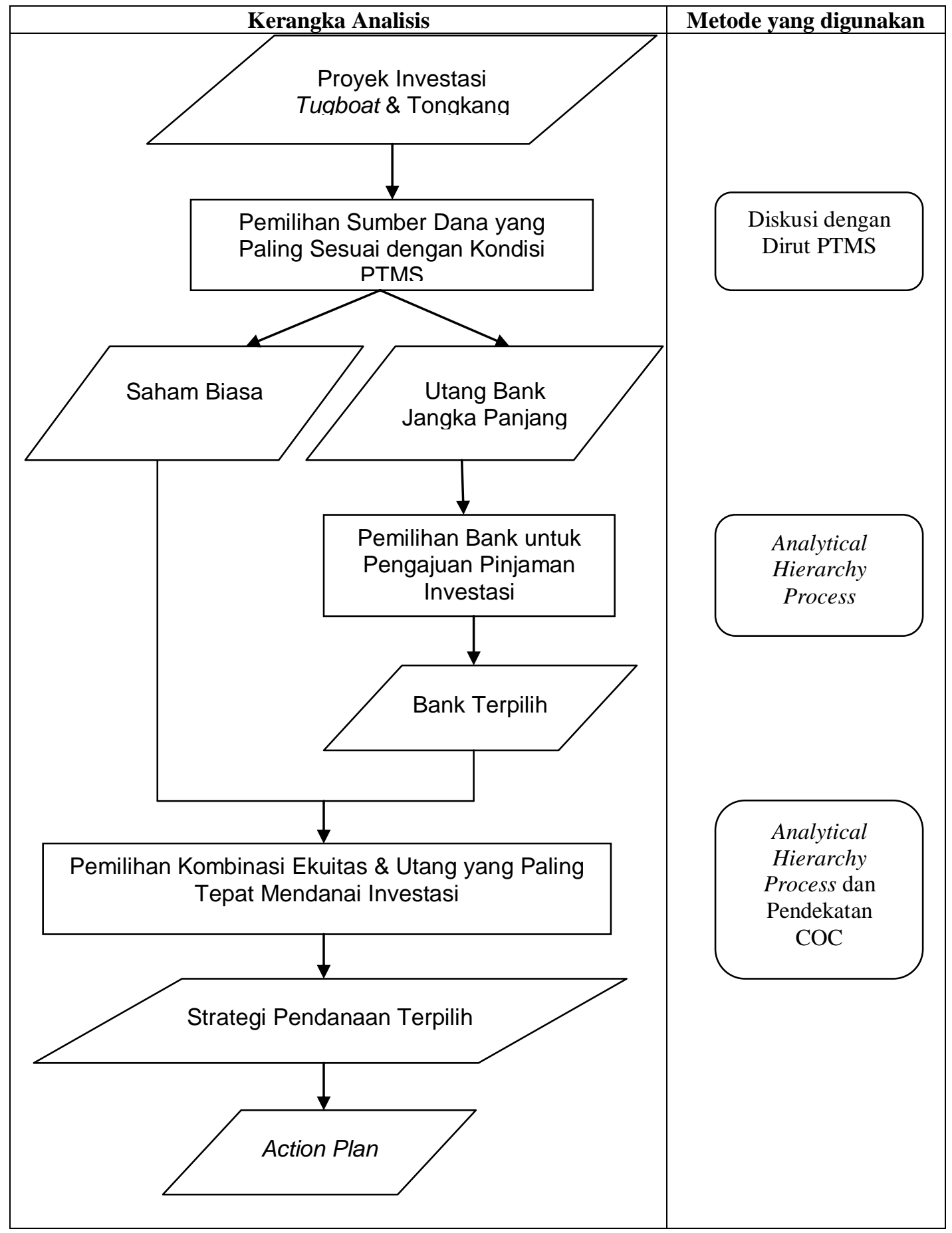

Gambar 1.

Kerangka Analisis Strategi Pendanaan Investasi Tugboat dan Tongkang di PTMS 
yaitu 20.145.000.000 IDR dimana besarnya laba ditahan sangat kecil (kurang dari $40 \%$ dari kebutuhan investasi) sehingga tidak dapat digunakan untuk mendanai proyek investasi tersebut. Dan untuk cadangan sendiri, PTMS memang tidak memiliki dana cadangan yang ditujukan untuk mendanai proyek investasi tugboat dan tongkang ini dan juga tidak memiliki dana cadangan umum.

Setelah diketahui bahwa instrumen pendanaan yang digunakan adalah saham dan hutang bank, maka dilakukan lagi pemilihan bank yang dijadikan acuan sebagai tempat peminjaman dengan menggunakan metode analytical hierarchy process. Setelah bank yang dijadikan acuan tempat peminjaman terpilih,maka dilakukan lagi proses pemilihan kombinasi prosentase,antara penggunaan hutang dan ekuitas.

Setelah data mengenai instrumen ekuitas yang digunakan adalah saham dan hutang bank, bank yang dijadikan acuan sebagai tempat peminjaman juga sudah terpilih, serta prosentase penggunaan hutang dan ekuitas yang digunakan juga sudah ditentukan, maka akan didapatkan strategi pendanaan terpilih berdasarkan alternatif yang terbaik berdasarkan persyaratan yang ada, oleh karena itu dapat dilakukan realisasi atau perwujudan perolehan dana.

\section{ANALISA STRATEGI PENDANAAN INVESTASI}

\subsection{Pemilihan Bank untuk Pengajuan Investasi Jangka Panjang dengan AHP}

Tujuan dari AHP pemilihan bank adalah memilih bank yang tepat untuk pengajuan investasi pinjaman jangka panjang,sedangkan kriteria yang digunakan untuk proses AHP adalah sebagai berikut : a. Cepat : Semakin cepat perolehan dana, dari pertama kali pengajuan pinjaman, hingga dana tersebut cair, maka dinilai semakin baik.

b. Mudah : Semakin sedikit syarat - syarat yang harus dipenuhi perusahaan dalam memperoleh pinjaman maka dinilai semakin baik.

c. Rate :Semakin kecil biaya bunga yang ditawarkan maka semakin menguntungkan bagi perusahaan karena semakin sedikit beban bunga yang harus ditanggung perusahaan.

d. Periode Pinjaman : Semakin panjang periode pinjaman maka semakin baik untuk perusahaan karena perusahaan memiliki waktu mencicil lebih panjang.

e. Jumlah Pinjaman : Semakin besar dana pinjaman yang dapat ditawarkan oleh bank maka semakin baik bagi perusahaan, karena perusahaan semakin sedikit menggunakan uangnya sendiri.

f. Agunan/Jaminan : Dalam hal ini, pinjaman investasi jangka panjang yang akan digunakan adalah pinjaman dengan agunan. Semakin sedikit agunan yang harus diserahkan oleh perusahaan maka semakin baik untuk perusahaan.

Kemudian alternatif pemilihan bank yang digunakan berdasarkan peringkat bank yang dinilai oleh Bank Indonesia (BI). Bank Indonesia menilai bank-bank yang ada untuk diberi peringkat dengan metode CAMEL, dimana metode penilaian tersebut sudah mempertimbangkan berbagai faktor, seperti aspek permodalan, aspek kualitas aset, aspek kualitas manajemen, aspek rentabilitas, dan aspek likuiditas. Berdasarkan hasil pemeringkatan oleh Bank Indonesia diperoleh hasil bahwa lima bank terbaik adalah : Bank Mandiri, Bank Rakyat Indonesia, Bank Central Asia, Bank Nasional Indonesia, dan Bank CIMB Niaga, maka kelima bank tersebut yang dijadikan alternatif dalam pemilihan bank untuk 
pengajuan pinjaman investasi jangka panjang.

Setelah menentukan goal,kriteria,dan alternatif,maka dilakukan pair comparison antara setiap kriteria. Setelah kriteria terpenting didapatkan,maka dilakukan pair comparison antara setiap alternatif terhadap setiap kriteria. Untuk dapat melakukan hal tersebut maka dibutuhkan data dibawah ini agar dapat membandingkan setiap kriteria dengan tingkat dan konsistensi yang sama.

Berdasarkan hasil pair comparison yang telah diolah menggunakan software expert choice 11, dapat dilihat bahwa alternatif terbaik berdasarkan kriteria Cepat, Mudah, Rate, Periode Pinjaman, Jumlah Pinjaman, dan Agunan, maka bank CIMB Niaga merupakan bank terbaik berdasarkan kriteria tersebut yang memberikan kecepatan pemberian pinjaman selama 14 hari, dokumen yang dipersyaratkan sejumlah 7 buah dokumen, bunga bank yang dipersyaratkan sebesar $12 \%-13 \%$, periode pelunasan pinjaman selama 5 tahun / lebih, jumlah pinjaman yang diberikan $90 \%$ dari total pinjaman, dan jaminan yang harus diberikan kepada bank adalah kapal tugboat dan tongkang itu sendiri dan jaminan lain yang dibutuhkan oleh bank.

\subsection{Penentuan Struktur Pendanaan (Kombinasi Presentase Ekuitas (Saham) dan Utang (Utang Bank Jangka Panjang)) dengan AHP}

Tujuan dari AHP struktur pendanaan adalah memilih kombinasi yang tepat/ prosentase yang tepat antara penggunaan hutang bank dan saham dari total kebutuhan dana yang ada.

Melihat tujuan pengambilan keputusan tersebut, dimana jenis utang dan jenis ekuitas yang akan digunakan sudah jelas dan pasti, maka ke-enam faktor yang ada dalam komponen FRICTO Analysis tidak semuanya relevan menjadi kriteria dalam pengambilan keputusan penentuan kombinasi presentase saham dan utang bank jangka panjang untuk mendanai proyek investasi. Faktor yang kurang relevan adalah Timing dan Other, karena untuk timing yang akan menjadi batasannya adalah kondisi pasar modal saat ini, sedangkan jenis ekuitas yang akan digunakan adalah saham pemilik yang tidak diperjualbelikan di pasar modal dan juga jenis utang yang digunakan adalah utang bank bukan utang obligasi yang diperjualbelikan di pasar modal, jadi kriteria timing dinilai kurang relevan dalam pengambilan keputusan. Sedangkan untuk kriteria other, tidak ada faktor lain yang dianggap penting untuk menjadi pertimbangan atau syarat dalam pengambilan keputusan tersebut. Melihat hal tersebut maka yang akan dijadikan kriteria dalam pengambilan keputusan tersebut adalah Fleksibilitas, Risk, Income, dan Control.

Oleh karena itu kriteria yang digunakan adalah :

a. Fleksibilitas : Jika struktur perndanaan semakin mendekati rating A maka semakin baik

b. Risk : Jika struktur pendanaan yang dihasilkan semakin jauh dari tingkat resiko kebangkrutan,maka akan semakin baik.

c. Income : Semakin kecil nilai weighted average cost of capital yang dihasilkan struktur pendanaan maka akan semakin baik

d. Control : Semakin tinggi penggunaan hutang,maka akan semakin baik. Hal tersebut disesuaikan dengan kebijakan manajemen, bahwa penggunaan saham yang semakin besar maka akan mengurangi kontrol manajemen perusahaan,maka penggunaan utang yang semakin besar akan semakin baik bagi perusahaan.

Untuk alternatif yang digunakan dari AHP struktur pendanaan ini adalah 
kombinasi antara penggunaan $10 \%$ saham dan $90 \%$ Utang, hingga penggunaan $90 \%$ Utang dan $10 \%$ saham, dari total kebutuhan dana sebesar 20.145.000.000 IDR.

Setelah tujuan, kriteria dan alternatif ditetapkan, maka selanjutnya adalah melakukan pair comparison antar kriteria. Setelah pair comparison antar kriteria dilakukan maka dilakukan pair comparison setiap alternatif terhadap setiap kriteria.

\subsubsection{Perhitungan Kriteria Fleksibilitas}

Untuk dapat mengetahui struktur pendanaan yang lebih fleksibel dibandingkan dengan yang lain, dilakukan perhitungan ICR dengan langkah - langkah :

a. Menghitung EBIT : EBIT yang digunakan adalah EBIT gabungan antara laporan laba/rugi tahun ke-1 PTMS ditambah dengan laporan laba/rugi atas investasi yang bernilai 18.058.184.608 IDR

b. Menghitung Total beban bunga : untuk perhitungan beban bunga dihitung dengan 2 skenario :

Skenario-1 : Asumsi : tingkat suku bunga = suku bunga yang ditetapkan oleh Bank CIMB Niaga.

Total Beban bunga yang dihitung dalam perhitungan ini merupakan proyeksi tahun ke-1 beban bunga perusahaan ditambah dengan beban bunga atas investasi, sehingga menghasilkan perhitungan ICR dan peringkat kredit perusahaan dengan cara EBIT / beban bunga, yang terlampir pada Tabel 2.

Tabel 2.

Peringkat Kredit Skenario-1

\begin{tabular}{|c|c||c|c|}
\hline Wd & $\begin{array}{c}\text { Total Beban } \\
\text { Bunga }\end{array}$ & $\begin{array}{c}\text { ICR } \\
\text { (EBIT/ total beban bunga) }\end{array}$ & $\begin{array}{c}\text { Peringkat } \\
\text { Kredit }\end{array}$ \\
\hline $10 \%$ & 2.868 .373 .670 & 6,30 & A \\
\hline $20 \%$ & 3.114 .231 .405 & 5,80 & A- \\
\hline $30 \%$ & 3.361 .084 .922 & 5,37 & A- \\
\hline $40 \%$ & 3.607 .938 .440 & 5,01 & A- \\
\hline $50 \%$ & 3.854 .791 .958 & 4,68 & A- \\
\hline $60 \%$ & 4.101 .645 .476 & 4,40 & BBB \\
\hline $70 \%$ & 4.348 .498 .993 & 4,15 & BBB \\
\hline $80 \%$ & 4.595 .352 .511 & 3,93 & BB+ \\
\hline \hline $90 \%$ & 4.842 .206 .029 & 3,73 & BB+ \\
\hline
\end{tabular}

Skenario-2: Asumsi : tingkat suku bunga $=$ berdasarkan peringkat kredit perusahaan

a. Menentukan $R f$ sebesar $7,7825 \%$ yang didapat dari obligasi pemerintah untuk tenor 10 tahun (Kontan, Rabu 15
Desember 2010) dan country risk sebesar 4,5\% (http://pages.stern.nyu. edu/ adamodar/), sehingga diperoleh suku bunga berdasar tiap peringkat kredit sebagai berikut ini (Tabel 3.). 
Tabel 3.

Suku Bunga atas Peringkat Kredit

\begin{tabular}{|l||l||l||}
\hline $\begin{array}{l}\text { Peringkat } \\
\text { Kredit }\end{array}$ & $\begin{array}{l}\text { Spread } \\
(\mathbf{\%})\end{array}$ & $\begin{array}{l}\text { Suku Bunga } \\
\boldsymbol{R f}+\text { spread +country risk }\end{array}$ \\
\hline \hline AAA & $0,50 \%$ & $12,7825 \%$ \\
\hline AA & $0,75 \%$ & $13,0325 \%$ \\
\hline A+ & $1,00 \%$ & $13,2825 \%$ \\
\hline A & $1,25 \%$ & $13,5325 \%$ \\
\hline A- & $1,50 \%$ & $13,7825 \%$ \\
\hline \hline BBB & $2,00 \%$ & $14,2825 \%$ \\
\hline BB+ & $3,50 \%$ & $15,7825 \%$ \\
\hline BB & $4,00 \%$ & $16,2825 \%$ \\
\hline B+ & $4,25 \%$ & $16,5325 \%$ \\
\hline B & $5,25 \%$ & $17,5325 \%$ \\
\hline B- & $5,50 \%$ & $17,7825 \%$ \\
\hline \hline CCC & $8,50 \%$ & $20,7825 \%$ \\
\hline CC & $10,00 \%$ & $22,2825 \%$ \\
\hline C & $12,00 \%$ & $24,2825 \%$ \\
\hline D & $15,00 \%$ & $27,2825 \%$ \\
\hline
\end{tabular}

b. Menentukan perkiraan beban bunga investasi berdasarkan perkiraan peringkat kredit perusahaan (Tabel 4.).

Tabel 4.

Perkiraan Peringkat Kredit

\begin{tabular}{|c|c|c||c||}
\hline Wd & $\begin{array}{c}\text { Perkiraan } \\
\text { Peringkat Kredit }\end{array}$ & Perkiraan Suku bunga (\%) & Perkiraan Beban bunga tongkang (IDR) \\
\hline \hline $10 \%$ & AAA & $12,7825 \%$ & 257.503 .463 \\
\hline \hline $20 \%$ & AA & $13,0325 \%$ & 525.079 .425 \\
\hline \hline $30 \%$ & A+ & $13,2825 \%$ & 802.727 .888 \\
\hline $40 \%$ & A & $13,5325 \%$ & 1.090 .448 .850 \\
\hline \hline $50 \%$ & A- & $13,7825 \%$ & 1.388 .242 .313 \\
\hline \hline $60 \%$ & BBB & $14,2825 \%$ & 1.726 .325 .775 \\
\hline \hline $70 \%$ & BB+ & $15,7825 \%$ & 2.225 .569 .238 \\
\hline \hline $80 \%$ & BB & $16,2825 \%$ & 2.624 .087 .700 \\
\hline $90 \%$ & B + & $16,5325 \%$ & 2.997 .424 .913 \\
\hline
\end{tabular}

Kemudian Beban Bunga investasi digabungkan dengan beban bunga perusa- haan sehingga diperoleh total beban bunga (Tabel 5.). 
Tabel 5.

Total Beban Bunga Skenario-2

\begin{tabular}{|c|c|}
\hline Wd & Total Beban bunga \\
\hline $10 \%$ & 2.883 .141 .349 \\
\hline $20 \%$ & 3.155 .830 .830 \\
\hline \hline $30 \%$ & 3.438 .592 .810 \\
\hline $40 \%$ & 3.731 .427 .290 \\
\hline $50 \%$ & 4.034 .334 .270 \\
\hline $60 \%$ & 4.377 .531 .251 \\
\hline $70 \%$ & 4.881 .888 .231 \\
\hline $80 \%$ & 5.285 .520 .211 \\
\hline \hline $90 \%$ & 5.663 .970 .941 \\
\hline
\end{tabular}

Dari nilai EBIT yang sama dengan skenario-1 maka ICR untuk skenario-2 ini didapat dengan rumus : EBIT / beban bunga (Tabel 6.).

Tabel 6.

Peringkat Kredit Skenario-2

\begin{tabular}{|c||c|c|}
\hline Wd i & ICR & $\begin{array}{c}\text { Peringkat Kredit } \\
\text { Sebenarnya }\end{array}$ \\
\hline \hline $10 \%$ & 6,26 & A \\
\hline \hline $20 \%$ & 5,72 & A- \\
\hline $30 \%$ & 5,25 & A- \\
\hline $40 \%$ & 4,84 & A- \\
\hline $50 \%$ & 4,47 & BBB \\
\hline $60 \%$ & 4,12 & BBB \\
\hline $70 \%$ & 3,70 & BB+ \\
\hline \hline $80 \%$ & 3,42 & BB \\
\hline $90 \%$ & 3,19 & BB \\
\hline \hline
\end{tabular}

\subsubsection{Perhitungan Kriteria Risk}

Untuk dapat melakukan pair comparison untuk kriteria risk, dihitung menggunakan altman Z'Score dengan rumus sebagai berikut :

$$
\begin{aligned}
& Z^{\prime}=0,717 *(\text { WC/TA })+0,847 *(\text { RE } / T A)+ \\
& 3,107 *(\text { EBIT/TA })+0,420 *(B V \text { of } \\
&\text { Equity/BV of debt })+0,998 *(\text { Sales } / T A) \\
& Z^{\prime}=0,717 *(0,113)+0,847 *(0,070)+ \\
& \\
& \quad 3,107 *(0,127)+0,420 *(0,098)+ \\
& \\
& 0,998 *(3,038)=3,727
\end{aligned}
$$

Nilai Z' $<1,23 \quad=$ Bankruptcy

Nilai Z' $1,23-1,93=$ Grey area

Nilai Z' $>2,90=$ Non bankruptcy

Variabel dalam rumus tersebut didapatkan dari proyeksi neraca dan laporan laba/rugi tahun ke-1,sehingga menghasilkan nilai Z' score (Tabel 7.). 
Tabel 7.

Hasil Perhitungan Altman Z'score

\begin{tabular}{|c||c||c|}
\hline $\begin{array}{c}\text { Wd } \\
\text { investasi }\end{array}$ & $\begin{array}{c}\text { Z' } \\
\text { Score }\end{array}$ & Risiko Kebangkrutan \\
\hline \hline $10 \%$ & 3,727 & Non Bankruptcy \\
\hline $20 \%$ & 3,726 & Non Bankruptcy \\
\hline $30 \%$ & 3,725 & Non Bankruptcy \\
\hline $40 \%$ & 3,725 & Non Bankruptcy \\
\hline $50 \%$ & 3,724 & Non Bankruptcy \\
\hline $60 \%$ & 3,723 & Non Bankruptcy \\
\hline $70 \%$ & 3,722 & Non Bankruptcy \\
\hline \hline $80 \%$ & 3,721 & Non Bankruptcy \\
\hline \hline $90 \%$ & 3,720 & Non Bankruptcy \\
\hline
\end{tabular}

\subsubsection{Perhitungan Kriteria Income}

Untuk dapat melakukan pair comparison untuk kriteria income, perlu dilakukan perhitungan weighted avarege cost of capital dengan langkah - langkah sebagai berikut :

a. Menghitung bottom up beta yang didapatkan dari rata - rata beta industri batubara di Indonesia yang diperoleh dari spreadsheet Damodaran (2010) yaitu sebesar 1,16

b. Menghitung unlevered beta $\left(\beta_{u}\right)$

$$
\begin{aligned}
\beta_{u}= & \text { Current } \beta /\left[1+\left(1-t_{\text {rata-rata industri }}\right) x\right. \\
& \text { Market D/ } \left.E_{\text {rata-rata industri }}\right] \\
= & 1,16 /\left[1+(1-23,63 \%)^{*} 17,36\right]=1,02
\end{aligned}
$$

c. Menghitung levered beta $\left(\beta_{L}\right)$ (Tabel 8.) pada setiap struktur pendanaan.

$$
\begin{aligned}
\beta_{L}= & \beta_{u} *\left[1+(1-t) D / E_{\text {firm }}\right] \\
= & 1,02 *[1+(1-25 \%) * 267,95 \%] \\
& =3,081
\end{aligned}
$$

Tabel 8.

Perhitungan Beta Levered

\begin{tabular}{|c||c||c|c||}
\hline $\begin{array}{c}\text { Wd } \\
\text { investasi }\end{array}$ & DER firm & $\boldsymbol{\beta}_{\boldsymbol{L}}$ & $\boldsymbol{\beta}_{\text {Ladjusment }}$ \\
\hline \hline $10 \%$ & $267,95 \%$ & 3,081 & 0,331 \\
\hline \hline $20 \%$ & $304,99 \%$ & 3,366 & 0,362 \\
\hline $30 \%$ & $350,33 \%$ & 3,714 & 0,399 \\
\hline $40 \%$ & $407,10 \%$ & 4,150 & 0,446 \\
\hline \hline $50 \%$ & $480,24 \%$ & 4,712 & 0,507 \\
\hline $60 \%$ & $578,05 \%$ & 5,463 & 0,587 \\
\hline \hline $70 \%$ & $715,50 \%$ & 6,518 & 0,701 \\
\hline \hline $80 \%$ & $922,87 \%$ & 8,111 & 0,872 \\
\hline \hline $90 \%$ & $1271,64 \%$ & 10,789 & 1,160 \\
\hline
\end{tabular}

d. Menentukan $\mathrm{R}_{\mathrm{f}}$ (return dari risk free asset) sebesar $7,7825 \%$ yang didapatk dari obligasi pemerintah untuk tenor 10 tahun (Kontan, Rabu 15 Desember 2010) e. Menentukan Risk Premium $\left(R_{m}-R_{f}\right)$ sebesar $9 \%$. 
f. Menghitung cost of equity (COE) (Tabel 9.) perusahaan pada setiap struktur

$$
\begin{aligned}
& =7,7825 \%+(0,331 * 9 \%) \\
& =10,76 \%
\end{aligned}
$$

pendanaan dengan metode CAPM.

$C O E=R_{f}+\left(\beta_{L} *\left(R_{m}-R_{f}\right)\right)$

Tabel 9.

Perhitungan COE Setiap Struktur Pendanaan

\begin{tabular}{|c||c|}
\hline \hline Wd investasi & COE \\
\hline $10 \%$ & $10,76 \%$ \\
\hline $20 \%$ & $11,04 \%$ \\
\hline $30 \%$ & $11,38 \%$ \\
\hline $40 \%$ & $11,80 \%$ \\
\hline $50 \%$ & $12,34 \%$ \\
\hline $60 \%$ & $13,07 \%$ \\
\hline $70 \%$ & $14,09 \%$ \\
\hline \hline $80 \%$ & $15,63 \%$ \\
\hline \hline $90 \%$ & $18,22 \%$ \\
\hline \hline
\end{tabular}

g. Menghitung cost of debt (COD) skenario1

Asumsi : $\mathrm{COD}=$ rate yang ditawarkan Bank

Dalam perhitungan COD ini, COD yang digunakan adalah effective rate yang ditawarkan bank CIMB Niaga sebesar $12,4 \%$,oleh karena itu perhitungan after tax COD dapat dilakukan sebagai berikut:

$$
\begin{aligned}
\text { After tax COD } & =(1-\operatorname{tax}) * \mathrm{COD} \\
& =(1-25 \%) * 12,4 \% \\
& =9,30 \%
\end{aligned}
$$

h. Menghitung cost of debt (COD) skenario-2

Asumsi : COD berdasarkan peringkat kredit perusahaan.

Penentuan peringkat kredit yang sudah dilakukan sebelumnya pada kriteria fleksibilitas menghasilkan hasil sebagai berikut (Tabel 10.):

Tabel 10.

Peringkat Kredit Sebenarnya dari Perhitungan Fleksibilitas Skenario-2

\begin{tabular}{|c|c||c||}
\hline Wd investasi & $\begin{array}{c}\text { Peringkat Kredit } \\
\text { Sebenarnya }\end{array}$ & Spread \\
\hline \hline $10 \%$ & A & $1,25 \%$ \\
\hline \hline $20 \%$ & A- & $1,50 \%$ \\
\hline \hline $30 \%$ & A- & $1,50 \%$ \\
\hline $40 \%$ & A- & $1,50 \%$ \\
\hline $50 \%$ & BBB & $2,00 \%$ \\
\hline \hline $60 \%$ & BBB & $2,00 \%$ \\
\hline
\end{tabular}

Penentuan alternatif hanya sampai $60 \%$,hal tersebut dikarenakan pada perhitungan kriteria flexibilitas penggunaan utang diatas $70 \%$ menghasilkan peringkat kredit perusahaan dibawah $\mathrm{BBB}$, dimana menurut ICRA,2005 peringkat kredit 
perusahaan dibawah BBB akan kurang menguntungkan bagi perusahaan jika ingin mengajukan pinjaman kembali di masa mendatang.

Hasil perhitungan di atas kemudian digunakan sebagai acuan menghitung COD pada setiap struktur pendanaan dengan rumus sebagai berikut (Tabel 11.):

$$
\begin{aligned}
& \text { Pretax } \mathrm{COD}= \mathrm{R}_{\mathrm{f}}+\text { Spread }+ \text { Country risk } \\
&= 7,7825 \%+1,25 \%+4,5 \%= \\
& 13,5325 \% \\
& \begin{aligned}
\text { After tax } \mathrm{COD}= & \text { Pretax } \mathrm{COD} *(1-\text { tax }) \\
& =13,5325 \% *(1-25 \%) \\
& =10,15 \%
\end{aligned}
\end{aligned}
$$

Tabel 11.

Perhitungan After Tax COD Skenario-2

i. Menghitung WACC skenario-1

\begin{tabular}{|c|c||c|}
\hline $\begin{array}{c}\text { Wd } \\
\text { investasi }\end{array}$ & Pretax COD & After tax COD \\
\hline \hline $10 \%$ & $13,5325 \%$ & $10,15 \%$ \\
\hline \hline $20 \%$ & $13,7825 \%$ & $10,34 \%$ \\
\hline \hline $30 \%$ & $13,7825 \%$ & $10,34 \%$ \\
\hline $40 \%$ & $13,7825 \%$ & $10,34 \%$ \\
\hline \hline $50 \%$ & $14,2825 \%$ & $10,71 \%$ \\
\hline \hline $60 \%$ & $14,2825 \%$ & $10,71 \%$ \\
\hline
\end{tabular}

$W A C C=\left(\right.$ After tax $\left.C O D * \mathrm{~W}_{\mathrm{d}}\right)+(C O E *$ $\left.\mathrm{W}_{\mathrm{e}}\right)$

$=(9,30 \% * 72,82 \%)+$

$(10,76 \% * 27,18 \%)$
$=9,70 \%$

Bobot penggunaang hutang dan ekuitas PTMS adalah sebagai berikut (Tabel 12.) :

Tabel 12.

Bobot Debt dan Ekuitas Skenario-1

\begin{tabular}{|c||c||c|}
\hline Wd & Wd firm & We firm \\
\hline $10 \%$ & $72,82 \%$ & $27,18 \%$ \\
\hline $20 \%$ & $75,31 \%$ & $24,69 \%$ \\
\hline \hline $30 \%$ & $77,79 \%$ & $22,21 \%$ \\
\hline $40 \%$ & $80,28 \%$ & $19,72 \%$ \\
\hline $50 \%$ & $82,77 \%$ & $17,23 \%$ \\
\hline $60 \%$ & $85,25 \%$ & $14,75 \%$ \\
\hline $70 \%$ & $87,74 \%$ & $12,26 \%$ \\
\hline $80 \%$ & $90,22 \%$ & $9,78 \%$ \\
\hline \hline $90 \%$ & $92,71 \%$ & $7,29 \%$ \\
\hline
\end{tabular}

Sehingga dapat dilakukan perhitungan WACC skenario-1 sebagai berikut (Tabel 13.): 
Tabel 13.

Perhitungan WACC Skenario-1

\begin{tabular}{|c||c||c|}
\hline $\begin{array}{c}\text { After tax } \\
\text { COD }\end{array}$ & COE & WACC \\
\hline \hline $9,30 \%$ & $10,76 \%$ & $9,70 \%$ \\
\hline $9,30 \%$ & $11,04 \%$ & $9,73 \%$ \\
\hline $9,30 \%$ & $11,38 \%$ & $9,76 \%$ \\
\hline $9,30 \%$ & $11,80 \%$ & $9,79 \%$ \\
\hline $9,30 \%$ & $12,34 \%$ & $9,82 \%$ \\
\hline $9,30 \%$ & $13,07 \%$ & $9,86 \%$ \\
\hline $9,30 \%$ & $14,09 \%$ & $9,89 \%$ \\
\hline \hline $9,30 \%$ & $15,63 \%$ & $9,92 \%$ \\
\hline $9,30 \%$ & $18,22 \%$ & $9,95 \%$ \\
\hline \hline
\end{tabular}

j. $\quad$ Menghitung WACC skenario-2

Perhitungan WACC untuk skenario-2 sama dengan skenario-1, namun yang berbeda adalah cost of debtnya mengikuti dari perhitungan after tax COD pada skenario-2. Sedangkan bobot penggunaan hutang dan ekuitasnya juga sama pada skenario-1 perhitungan WACC

Sehingga menghasilkan perhitungan WACC skenario-2 sebagai berikut (Tabel 14.) :

Tabel 14.

Perhitungan WACC Skenario-2

\begin{tabular}{|c||c|c||}
\hline After tax COD & COE & WACC \\
\hline $10,15 \%$ & $10,76 \%$ & $10,32 \%$ \\
\hline \hline $10,34 \%$ & $11,04 \%$ & $10,51 \%$ \\
\hline $10,34 \%$ & $11,38 \%$ & $10,57 \%$ \\
\hline $10,34 \%$ & $11,80 \%$ & $10,63 \%$ \\
\hline \hline $10,71 \%$ & $12,34 \%$ & $10,99 \%$ \\
\hline $10,71 \%$ & $13,07 \%$ & $11,06 \%$ \\
\hline
\end{tabular}

\subsubsection{Perhitungan Kriteria Control}

Berdasarkan kebijakan PTMS yang lebih memilih penggunaan hutang lebih banyak, maka prioritas dalam perhitungan pair comparison untuk kriteria control maka prioritas tertinggi pada kriteria control ada pada penggunaan hutang $90 \%$ dan $10 \%$ ekuitas, dan seterusnya.

\subsubsection{Hasil Sintesa Pair Comparison untuk AHP Struktur Pendanaan}

Setelah data dari perhitungan setiap kriteria telah dihitung dan didapatkan, maka dapat dilakukan dilakukan pair comparison antara setiap alternatif terhadap setiap kriteria, hal tersebut dilakukan agar proses pair comparison dapat dilakukan dengan tingkat perbandingan dan konsistensi yang sama,demikian juga dengan proses pair comparison antar kriteria.

Perhitungan dengan dua skenario di atas dilakukan karena keterbatasan data yang dimiliki, dimana kami sulit memperoleh keputusan besaran suku bunga pinjaman bank. Hampir setiap bank tidak bisa menentukan secara tepat besaran suku bunga yang akan ditetapkan atas suatu pinjaman investasi sebelum mereka melakukan analisa 
keuangan secara detail. Dan untuk melakukan analisa keuangan tersebut harus sudah ada kesepakatan untuk melakukan pinjaman secara sah, maka karena hal tersebut tidak mungkin kami lakukan saat ini, maka kami membuat dua skenario yang mendekati kondisi sesungguhnya.

Dua skenario tersebut adalah : Skenario-1 dimana COD diasumsikan sebesar $12,4 \%$, yaitu sama dengan perkiraan suku bunga efektif yang ditawarkan oleh Bank CIMB Niaga. Berdasarkan informasi yang kami peroleh dari Bank CIMB Niaga, untuk pinjaman investasi jangka panjang biasanya bunganya berkisar $12-13 \%$. Kami mengasumsikan negosiasi PTMS dengan CIMB Niaga bisa memperoleh kesepakatan pada suku bunga terendah, yaitu $12 \%$ dan suku bunga ini berlaku pada setiap alternatif struktur pendanaan, karena sebelumnya PTMS juga sudah bekerjasama dengan CIMB Niaga dalam melakukan pinjaman jangka pendeknya, sehingga lebih mudah dalam memperoleh kesepakatan tersebut. Namun karena ada biaya-biaya lain yang harus dikeluarkan PTMS untuk memperoleh pinjaman tersebut, maka diperoleh suku bunga efektifnya adalah sebesar 12,4\%. Sedangkan pada Skenario-2, lebih disesuaikan dengan kondisi keuangan PTMS akibat adanya investasi tugboat dan tongkang. Struktur pendanaan dengan proporsi utang yang lebih besar akan mengakibatkan semakin besar pula risiko keuangan yang dihadapi oleh perusahaan. Semakin besar rasio utang akan menurunkan peringkat kredit perusahaan, sehingga meningkatkan spread yang mengakibatkan meningkatnya COD.

Dari hasil sintesa pair comparison diatas didapatkan bahwa alternatif struktur pendanaan terbaik menurut skenario 1 dan skenario 2 adalah penggunaan $10 \%$ utang dan $90 \%$ saham.

\subsection{Action Plan}

5.3.1 Pengelolaan Pembayaran Utang kepada Bank CIMB Niaga dan Pembayaran deviden kepada Shareholders Skenario-1

Setelah proposal diajukan baik kepada pihak shareholders dan kepada pihak bank dan dana yang dibutuhkan diperoleh, maka diperlukan pengelolaan dalam pembayaran utang dan pemberian deviden kepada shareholders.

Berdasarkan keputusan bahwa penggunaan utang sebesar $10 \%$ dari kebutuhan dana, dan penggunaan saham adalah sebesar $90 \%$ dari kebutuhan dana, dimana kebutuhan dananya adalah sebesar 20.145.000.000 IDR, maka total utang yang harus dibayarkan kepada bank CIMB Niaga adalah sebesar 2.014.500.000 IDR, dan total saham yang akan diinvestasikan pada tugboat dan tongkang ini sebesar 18.130.500.000 IDR.

a. Pengelolaan pembayaran utang kepada bank CIMB Niaga skenario-1

Pembayaran utang kepada bank CIMB Niaga akan dilakukan selama 8 tahun dengan suku bunga $12 \%$ dari jumlah pinjaman sebesar 2.014.500.000 IDR, oleh karena itu untuk tahun ke-1 sampai tahun ke-8 cicilan pokok dan bunga.

b. Pengelolaan Pemberian Deviden Kepada Shareholders Skenario-1

Setiap Investor, tentu menginginkan return atau tikat pengembalian dalam setiap investasinya, berdasarkan pembahasan sebelumnya, bahwa return yang diharapkan sebesar $10,76 \%$ dari kebutuhan investasi atau sebesar 1.951.628.034 IDR, pada hakikatnya pembayaran deviden harus dilakukan per tahun,tetapi melihat dengan kondisi internal perusahaan, jika net income perusahaan tidak mencukupi pembayaran deviden, maka deviden 
tidak dibagikan di tahun tersebut, tetapi melihat proyeksi laporan laba/rugi perusahaan PTMS selama 8 tahun, bahwa Net Income yang dihasilkan oleh perusahaan masih bernilai positif, bahkan setelah dilakukan pembagian deviden pun, EVA-nya masih menunjukkan nilai positif, sehingga diharapkan pembayaran deviden dapat dilakukan secara rutin setiap tahun.

\subsubsection{Pengelolaan Pembayaran Utang kepada Bank CIMB Niaga dan Pembayaran Deviden kepada Shareholders Skenario-2}

Setelah proposal diajukan baik kepada pihak shareholders dan kepada pihak bank dan dana yang dibutuhkan diperoleh, maka diperlukan pengelolaan dalam pembayaran utang dan pemberian deviden kepada shareholders.

Berdasarkan keputusan bahwa penggunaan utang sebesar $10 \%$ dari kebutuhan dana, dan penggunaan saham adalah sebesar 90\% dari kebutuhan dana, dimana kebutuhan dananya adalah sebesar 20.145.000.000 IDR, maka total utang yang harus dibayarkan kepada bank CIMB Niaga adalah sebesar 2.014.500.000 IDR, dan total saham yang akan diinvestasikan pada tugboat dan tongkang ini sebesar 18.130.500.000 IDR.

a. Pengelolaan pembayaran utang kepada bank CIMB Niaga skenario-2

Pembayaran utang kepada bank CIMB Niaga akan dilakukan selama 8 tahun dengan suku bunga yang besarnya $13,53 \%$ dari jumlah pinjaman.

b. Pengelolaan pemberian Deviden kepada Shareholders Skenario-2
Setiap Investor, tentu menginginkan return atau tingkat pengembalian dalam setiap investasinya, berdasarkan pembahasan sebelumnya, bahwa return yang diharapkan sebesar 10,76\% dari kebutuhan investasi atau sebesar 1.951.628.034 IDR, pada hakikatnya pembayaran deviden harus dilakukan per tahun,tetapi melihat dengan kondisi internal perusahaan, jika net income perusahaan tidak mencukupi pembayaran deviden, maka deviden tidak dibagikan di tahun tersebut, tetapi melihat proyeksi laporan laba/rugi perusahaan PTMS selama 8 tahun bahwa Net Income yang dihasilkan oleh perusahaan masih bernilai positif, bahkan setelah dilakukan pembagian deviden pun, EVA-nya masih menunjukkan nilai positif, sehingga diharapkan pembayaran deviden dapat dilakukan secara rutin setiap tahun.

\subsubsection{Action Plan untuk Memastikan Terpenuhinya Kewajiban Pemba- yaran Utang dan Deviden atas Investasi Tugboat dan Tongkang}

Setelah memperoleh dana pinjaman

dari bank dan dana investasi dari shareholders, maka PTMS harus memastikan bahwa mereka dapat memenuhi kewajiban pembayaran cicilan pokok dan bunga pinjaman kepada bank, serta pembayaran deviden kepada shareholders. Untuk memastikan hal tersebut, hal-hal yang harus dilakukan oleh PTMS adalah sebagai berikut (Tabel 15.): 
Tabel 15.

Action Plan untuk Memastikan Terpenuhinya Kewajiban Pembayaran Utang dan Deviden atas Investasi Tugboat dan Tongkang

\begin{tabular}{|c|c|}
\hline $\begin{array}{c}\text { Tahun } \\
\text { ke- }\end{array}$ & Action \\
\hline $1-5$ & $\begin{array}{l}\text { - Meningkatkan penjualan sama besar dengan saat ini, yaitu berkisar } 389 \% \\
\text { (high growth). } \\
\text { - Optimasi penggunaan tugboat dan tongkang untuk mendukung proses } \\
\text { feeder dan transhipment }(27 \mathrm{x} \text { feeder/tahun dengan kapasitas } \\
\text { 5500MT/angkut }+24 \mathrm{x} \text { transhipment/tahun dengan kapasitas } \\
\text { 5000MT/angkut). } \\
\text { - Menekan biaya pokok penjualan dan biaya operasional. } \\
\text { - Meningkatkan akses ke produsen batubara. } \\
\text { - Meningkatkan kerjasama eksklusif dengan pemiliki Kuasa Penambangan } \\
\text { dalam rangka memastikan kontinuitas tersedianya batubara dan menekan } \\
\text { biaya pokok penjualan. }\end{array}$ \\
\hline $6-8$ & $\begin{array}{l}\text { - Meningkatkan penjualan berkisar } 20 \% \text { (stable growth). } \\
\text { - Optimasi penggunaan tugboat dan tongkang untuk mendukung proses } \\
\text { feeder dan transhipment }(27 \mathrm{x} \text { feeder/tahun dengan kapasitas } \\
\text { 5500MT/angkut }+24 \mathrm{x} \text { transhipment/tahun dengan kapasitas } \\
\text { 5000MT/angkut). } \\
\text { - Mempertahankan efektivitas dan efisiensi kegiatan operasional. }\end{array}$ \\
\hline
\end{tabular}

\section{KESIMPULAN DAN SARAN}

\subsection{Kesimpulan}

Kesimpulan yang dapat diperoleh dari pembahasan yang telah dilakukan adalah :

a. Untuk melakukan investasi kapal 270 feet untuk mendukung proses feeder Bintang Ninggi-Timbau dan transhipment Timbau-Taboneo dibutuhkan dana sebesar 20.145.000.000 IDR.

b. Untuk mendanai proyek investasi tersebut, sumber dana yang dapat digunakan adalah dana internal yang berasal dari saham biasa dan dana eksternal yang berasal dari utang bank jangka panjang.

c. Untuk memperoleh pinjaman investasi jangka panjang dari bank, dipilih bank yang paling tepat untuk diajukan pinjaman dengan metode AHP (Analytical Hierarchy Process). Berdasarkan penilaian yang dilakukan oleh Manajer Keuangan dan Direktur PTMS terhadap kriteria pemilihan bank, diperoleh prioritas kriteria dari yang paling penting adalah : jumlah maksimal pinjaman, tingkat suku bunga, periode pelunasan pinjaman, kemudahan memperoleh dana, kecepatan memperoleh dana, dan terakhir adalah jaminan.

d. Berdasarkan penilaian terhadap ke-enam kriteria tersebut, diperoleh Bank yang paling tepat untuk diajukan dana pinjaman investasi jangka panjang adalah Bank CIMB Niaga.

e. Untuk mendanai investasi tugboat dan tongkang tersebut, dipilih struktur pendanaan yang paling tepat dengan metode AHP (Analytical Hierarchy Process). Pemilihan struktur pendanaan dilakukan berdasarkan empat kriteria dengan prioritas dari yang paling penting : income, flexibility, control, dan risk. 
f. Perhitungan dilakukan dengan dua skenario : (1) COD diasumsikan sama dengan suku bunga efektif yang ditawarkan oleh bank CIMB Niaga, yaitu $12,4 \%$ dan berlaku sama pada setiap struktur pendanaan, dan (2) COD diasumsikan nilainya berubah pada setiap struktur pendanaan, disesuaikan dengan peringkat kreditnya.

g. Berdasarkan penilaian terhadap ke-empat kriteria tersebut pada skenario-1 dan skenario-2, diperoleh struktur pendanaan yang paling tepat adalah kombinasi $10 \%$ utang bank jangka panjang-90\% saham, yaitu 2.014.500.000 IDR utang bank jangka panjang dan 18.130.500.000 IDR saham.

h. Biaya modal yang dibutuhkan untuk stuktur pendanaan skenario-1 adalah $10,76 \%$ untuk cost of equity dan $9,30 \%$ untuk cost of debt.

i. Biaya modal yang dibutuhkan untuk stuktur pendanaan skenario-1 adalah $10,76 \%$ untuk cost of equity dan $13,53 \%$ untuk cost of debt.

j. Action plan dalam upaya memperoleh dana pinjaman dari bank dan dana investasi dari shareholders dilakukan dalam jangka waktu kurang lebih 2,5 bulan.

k. Action plan untuk memastikan pemenuhan kewajiban PTMS dalam membayar cicilan dan bunga pinjaman serta deviden atas investasi yang dilakukan adalah mempertahankan pertumbuhan penjualan yang tinggi selama 5 tahun ke depan, yaitu sebesar $389 \%$, lalu mempertahankan pertumbuhan yang stabil di tahun-tahun selanjutnya, yaitu sebesar $20 \%$, serta mengoptimasi operasional tugboat dan tongkang tersebut dalam mendukung proses feeder dan transhipment, yaitu $27 \mathrm{x}$ feeder/tahun dengan kapasitas 5500MT/ angkut dan $24 \mathrm{x}$ transhipment / tahun dengan kapasitas 5000MT/angkut.

\subsection{Saran}

Perusahaan harus bisa bernegosiasi dengan baik dengan pihak shareholders perihal return yang akan diterima oleh para shareholders, agar perusahaan dapat memberikan return yang sesuai dengan kondisi pasar dan shareholders tidak bisa menuntut return yang terlampau tinggi. Selain itu perusahaan juga harus bisa bernegosiasi dengan baik dengan pihak bank perihal tingkat suku bunga pinjaman yang harus ditanggung perusahaan. Melihat kondisi keuangan PTMS dalam kondisi yang baik, dapat dilihat dari perhitungan $Z^{\prime}$-Score yang menunjukkan hasil tidak adanya risiko kebangkrutan walau dengan pinjaman 90\% dari kebutuhan dana sekalipun, selama ini PTMS memiliki hubungan kerjasama keuangan dengan pihak bank CIMB Niaga yang sangat baik dan sehat, serta PTMS juga memiliki induk perusahaan yang besar dan dapat menjamin jika terjadi risiko kebangkrutan sekalipun, hal-hal tersebut dapat dijadikan sebagai dasar yang kuat untuk PTMS melakukan negosiasi dengan pihak bank agar suku bunga yang ditetapkan adalah suku bunga terendah dari yang diperkirakan oleh bank.

Selain itu, hal penting lainnya yang harus diperhatikan adalah pemenuhan kewajiban atas dana investasi dan utang yang diperoleh oleh perusahaan. Untuk dapat memenuhi kewajibannya tersebut, perusahaan harus dapat melaksanakan action plan yang sudah disusun dengan baik. 


\section{DAFTAR PUSTAKA}

Abdul, Halim. Analisis Investasi. Jakarta : Salemba Empat. 2005.

Clarke, Roger, dan Grant McQueen. Some Indicators of Firm's Risk and Debt Capacity. 2001.

Damodaran, Aswath. Investment Valuation, Tools and Techniques for Determining the Value of Any Asset. $2^{\text {nd }}$ ed. New York : John Wiley \& Sons, Inc. 2002.

Djohanputro, Bramantyo. Manajemen Keuangan Korporat. Jakarta : Penerbit PPM. 2008.

Kester, George W., dan Scott A. Hoover, "FRICTO Analysis: A Framework for Making Capital Structure and Financing Decisions," Journal of Financial Education, Vol. 31, pp. 61-68. 2005

Mulyono, S. Teori Pengambilan Keputusan. Jakarta : Penerbit Fakultas Ekonomi UI. 1996.

Nurdiana, Efi. Analisis Pemilihan Bank Sebagai Tempat Menabung dengan Metode Analytical Hierarchy Process. Universitas Gunadarma.

Riyanto, Bambang. Dasar-dasar Pembelanjaan Perusahaan. Edisi 4. Yogyakarta: BPFE, 2001.

Saaty, Thomas L. Pengambilan Keputusan Bagi Para Pemimpin. Jakarta : Pustaka Binaman Pressindo. 1993.

Saaty, Thomas L. The Analytical Hierarchy Process : Planning, Priority Setting, Resource Allocation. Pittsburgh : University of Pittsburgh Pers. 1990.

Sudarsono, Dharma. Penerapan Analytical Hierarchy Process (AHP) Untuk Pemilihan Metode Audit PDE Oleh Auditor Internal. Proceeding Komputer dan Sistem Intelijen. Jakarta : Universitas Gunadarma. 2004.

Sulistiyono. Modal. Jakarta : STIE Indonesia.

Sundjaja, Ridwan S., dan Inge Barlian. Edisi 5. Manajemen Keuangan 2. Bandung : Literata Lintas Media. 2003.

White, Susan. Readers Digest Association : Debt or Equity. University of Maryland.

White, Gerald, Ashwinpaul C Sondhi, dan Dov Fried. The Analysis and Use of Financial Statements. $3^{\text {rd }}$ ed. New York : John Wiley \& Sons, Inc. 2003.

http://icraindonesia.com/uploaded/pdf/PT\%20ICRA\%20Indonesia-Corporate\%20Rating-

Methodology\%20_Bahasa\%20Indonesia_.pdf

http://jalaludinweb.wordpress.com

http://pages.stern.nyu.edu/ adamodar/

http://www.cob.sfasu.edu/kjones/F333/Lecture\%20Notes/12A.pdf

http://www.docstoc.com/docs/3447768/Biaya-Modal-(Cost-Of-Capital) 